\section{EL CONCEPTO DE GÉNERO COMO HERMENÉUTICA DE LA SOSPECHA: DE LA BIOLOGÍA A LA FILOSOFÍA MORAL Y POLÍTICA}

\author{
Alicia H. Puleo \\ Cátedra de Estudios de Género \\ Universidad de Valladolid \\ puleo@flfc.uva.es
}

Cómo citar este artículo/Citation: Puleo, A. H. (2013). "El concepto de género como hermenéutica de la sospecha: de la Biología a la Filosofía Moral y Política". Arbor, 189 (763): a070. doi: http://dx.doi.org/10.3989/arbor.2013.763n5007

Recibido: 13 julio 2012. Aceptado: 6 junio 2013

RESUMEN: Este artículo trata sobre el concepto de género como un caso paradigmático de frontera entre lo biológico y lo cultural. Examina los orígenes históricos olvidados de la idea de género como construcción social durante la llustración, su definición en el siglo XX por oposición a lo biológico y su influencia en la elaboración de leyes orientadas hacia la igualdad entre mujeres y hombres. Atiende también a la creciente absorción del concepto de sexo por el de género en los debates más recientes. Para finalizar, plantea la necesidad de que la hermenéutica de la sospecha de género continúe utilizándose para implementar políticas de igualdad y, al mismo tiempo, sirva para desvelar el sesgo androcéntrico en la cultura.

PALABRAS CLAVE: Género; Igualdad; Androcentrismo.

\section{THE CONCEPT OF GENDER AS A HERMENEUTICS OF SUSPICION: FROM BIOLOGY TO MORAL AND POLITICAL PHILOSOPHY}

Copyright: (C) 2013 CSIC. Este es un artículo de acceso abierto distribuido bajo los términos de la licencia Creative Commons Attribution-Non Commercial (by-nc) Spain 3.0.

ABSTRACT: This article discusses the concept of gender as a paradigmatic case of the boundary between Biology and Culture. It examines the forgotten historical origins of the idea of gender as social construction during the Enlightenment, its definition in the twentieth century in opposition to Biology and its influence on the development of legislation geared towards equality between women and men. Also covers the increasing absorption of the concept of sex by gender in the most recent discussions. Finally, it suggests that the hermeneutics of suspicion must continue to play a huge role in implementing gender equality policies and, at the same time, to unveil androcentric biais in culture.

KEYWORDS: Gender; Equalit; Androcentrism.

"No se nace mujer, se llega a serlo" 
A más de cien años del nacimiento de la filósofa existencialista Simone de Beauvoir, me parece de toda justicia elegir como epígrafe de estas líneas la frase más famosa de su libro El Segundo Sexo. Aunque esta obra de 1949 no incluya el término género, incorporado más tarde a las ciencias sociales y humanas, plantea claramente el significado de construcción cultural que "género" tiene actualmente. Es más, puede decirse que, con ella, se inaugura el debate del siglo XX sobre lo biológico y lo cultural en la diferencia de los sexos. Una polémica que no se reduce al plano teórico sino que ha tenido, y conserva, un enorme poder de transformación de las leyes y de la sociedad.

Como se sabe, Paul Ricoeur calificó de "maestros de la sospecha" a Nietzsche, a Freud y a Marx. Los tres habrían cultivado una "herméneutique du soupçon". El calificativo de hermenéutica de la sospecha hace referencia a aquellas teorías que suponen que, por debajo de nuestra aparente racionalidad y voluntad libre, hay elementos que dirigen nuestra acción sin que lo advirtamos. Aun cuando no aceptemos totalmente las teorías psicoanalíticas, deberemos reconocer que Freud supo señalar que no siempre nuestras conductas son conscientes. Tanto él como sus discípulos estudiaron las fuerzas que dirigen nuestra acción y que en su teoría reciben el nombre de libido. Nietzsche, otro gran maestro de la sospecha, planteó que por debajo de nuestra conducta y del desarrollo civilizatorio subyacía la Voluntad de Poder como una corriente subterránea fundante de toda realidad. Su crítica a la cultura se encaminó a la búsqueda del pudenda origo de los valores. Emprendió su genealogía de la moral como una tarea desmitificadora y liberadora. Por su parte, Marx denunció la ideología como falsa conciencia y nos enseñó a mirar, analizar y preguntarnos hasta qué punto nuestros prejuicios, nuestros pensamientos, nuestras actitudes y las grandes realizaciones del mundo simbólico no tenían un origen de clase. Independientemente del fracaso de la propuesta política marxista, la idea de que la pertenencia de clase configura la subjetividad es una aportación definitiva del materialismo dialéctico a las ciencias sociales.

¿Podemos asimilar la teoría de género a una hermenéutica de la sospecha? ¿Qué nos permite descubrir el concepto de género? ¿Cuál es la sospecha que plantea? Su sospecha es que la asignación social de sexo tiene que ver con la forma en que pensamos, sentimos y actuamos. En una palabra, se trata de otra contribución a la certeza de que no somos tan libres, originales ni racionales como se suponía en el inicio de la Modernidad. Pero su interés no se reduce a esta constatación. El concepto de género facilita también elementos para una hermenéutica de la sospecha que nos permite desestabilizar nuestras identidades, mirar críticamente la organización de la sociedad por sexos y plantearnos su transformación.

\section{UN CASO PARADIGMÁTICO DE FRONTERA ENTRE LO BIOLÓGICO Y LO CULTURAL}

El concepto de género se define en el mundo anglosajón a mediados del siglo XX para designar las actitudes, características y roles esperados por el entorno en un niño o niña a partir de la identificación de su sexo según sus caracteres anatómicos externos. Así, mientras sexo se refiere a los elementos biológicos, gender aludirá a lo adquirido, a lo proveniente de la educación, entendida esta en un sentido muy amplio.

Es sabido que la categoría de género ha ido ganando importancia en las últimas décadas. Gracias al análisis social que ha permitido esta herramienta conceptual, se han desarrollado las políticas de acción positiva que tuvieron su origen en EEUU y se han extendido a gran número de países (Osborne, 2008). En 1999, el Tratado de Ámsterdam consagró la igualdad entre los sexos como un objetivo de la Unión Europea que han de procurar las políticas comunes y de los estados miembros. Este principio, así como las Directivas europeas posteriores de 2002 y 2004 (referidas a la aplicación del principio de igualdad de trato en el acceso a la formación, al empleo, a las condiciones de trabajo, a la promoción profesional y a los bienes y servicios), son recogidas en nuestro país por la Ley Orgánica para la Igualdad efectiva entre mujeres y hombres de marzo de 2007. Hay leyes que incluso incorporan el término género en su denominación misma. Este avance del concepto crítico de género no se ha producido sin encontrar resistencias. Una de las numerosas dificultades a las que se enfrentó la Ley Integral contra la Violencia de Género fue justamente una fuerte oposición a la utilización de los conceptos de género y violencia de género. Durante su elaboración, tuvo lugar un encendido debate en los medios de comunicación. Ante el anuncio del Proyecto de Ley, la Real Academia se manifestó indignada contra lo que consideraba una mala traducción del inglés cuando se tenía una palabra como "sexo" que, supuestamente, designaba lo mismo. Para la institución encargada de preservar la lengua española, se trataría simplemente de un barbarismo. En su informe especial con motivo de la preparación de la Ley, sostiene que debería llamarse Ley contra la violencia doméstica, admitiendo solo que, en todo caso, se podría agregar "y por razón de sexo" para incluir los casos en que el agresor no conviviera con la mujer. 
Al promulgarse la ley, se oficializó el uso común del término fuera del ámbito del feminismo y de las ciencias sociales que ya lo habían adoptado mucho tiempo antes. Sin embargo, obedeciendo a la Real Academia y por ignorancia del significado del nuevo término, los periodistas suelen resistirse aún a hablar de violencia de género y, a menudo, prefieren seguir empleando la expresión violencia doméstica ${ }^{1}$.

Yo he sostenido en otro lugar (Puleo, 2008) que ese debate no era realmente un debate lingüístico, sino un debate político en el sentido amplio de "política" como relaciones de poder en todos los niveles de la sociedad. Porque el concepto de género tiene un componente crítico que lo hace peligroso para quienes no desean cambios en la organización sexuada de la sociedad. De ahí tanta indignación por un supuesto atropello a la lengua española, al tiempo que se acepta multitud de palabras tomadas del inglés para referirse, por ejemplo, a la informática. Hasta el término gay es aceptado y comienza a ser incluido en los diccionarios. En cambio, género solo lo ha recogido el Diccionario de María Moliner. Atento al uso y la evolución de la lengua junto con la sociedad, en su tercera edición, presentada en septiembre de 2007, añadió una sexta acepción a la palabra género: "Sexo. Referido especialmente a las diferencias sociales o culturales motivadas por el sexo de las personas: discriminación por razones de género. Violencia de género".

Esta no es una casualidad, es un caso de violencia simbólica en el sentido definido por Pierre Bourdieu. La violencia simbólica consiste en privar al grupo oprimido de los instrumentos conceptuales que le permitirían analizar su opresión. A menudo, conscientes de que el término feminismo se halla injustamente estigmatizado, convertido en significante que, en el imaginario popular, generalmente remite a voluntad de invertir la dominación, prepotencia hembrista ${ }^{2}$, histeria y exceso, quienes realizan investigación o formación en torno a la desigualdad entre los sexos se limitan a hablar de género, categoría que tiene la ventaja de remitir a las ciencias sociales. Aducir que no existe en la lengua castellana, resistirse a su introducción es más que un problema lingüístico. Considero que esta polémica oculta lo que realmente está en juego: la eliminación de categorías de impugnación de un antiguo orden patriarcal que distribuye los roles de sexo según un modelo estratificado.

El concepto de género, como lo que es construido frente a lo que es recibido, fue asumido por los movimientos feministas en el siglo XX, dando lugar a un cambio espectacular en las sociedades occidentales. Quizás hemos perdido la perspectiva histórica y no lo percibimos, pero si pensamos cómo era Occidente en el siglo XIX, veremos que se trata de una transformación impresionante consistente en la salida del colectivo femenino de la reclusión doméstica para comenzar a ocupar, aunque sea parcialmente, el espacio público de los estudios superiores, las profesiones liberales y la política. La conquista de los derechos fundamentales, de la igualdad formal y la actual reivindicación de equidad en el acceso a los recursos y al reconocimiento (Rubio, 1997; Fraser, 1997) han sido y son el objetivo de ese movimiento social llamado feminismo. Sus demandas han pasado a la agenda política internacional: "En la actualidad, la crítica a la desigualdad sexual se ha convertido, gracias a las luchas feministas, en un elemento central de la cultura política de Occidente" (De Miguel \& Cobo, 1997: 204). Este espectacular avance en la igualdad democrática se ha logrado, entre otras razones, gracias a la utilización del concepto de género que ha permitido desnaturalizar las características adscriptivas femeninas y masculinas, facilitando la deconstrucción de lo que parecía ser un destino biológico ineluctable.

Comparando, incluso, la sociedad europea actual con la de hace cincuenta años, podemos decir que los papeles sociales de hombres y mujeres son hoy mucho más permeables, mucho más fluidos. Ambos sexos han ganado en libertad porque hoy reconocemos que hombres y mujeres somos, al menos parcialmente, producto de una construcción social. Indudablemente, el caso del género es paradigmático de la relación de frontera entre lo biológico y lo cultural.

\section{LOS ORÍGENES FILOSÓFICOS OLVIDADOS DE UN CONCEPTO REVOLUCIONARIO}

Si buscamos los orígenes lejanos del concepto de género, veremos que posee una larga historia. He sostenido que se encuentra ya prefigurado en algunos pensadores ilustrados (Puleo, 1991). Desde finales del siglo XVII y a lo largo del XVIII, se plantea un gran debate sobre qué es lo adquirido y qué es lo natural en los papeles de hombres y mujeres. Esta polémica surge por diversas causas. Por un lado, se alimenta del conocimiento de otras culturas aportado por los relatos de misioneros y viajeros de la época que describen las costumbres de Oriente y del Nuevo Mundo. Las sociedades europeas comienzan a mirarse en el espejo del Otro, sea este la milenaria China, los pueblos polinésicos o los indígenas americanos (Puleo, 1996). En el debate de la incipiente antropología encontrará un 
lugar privilegiado la especulación acerca de lo que es femenino y masculino por naturaleza. No en vano es el momento de gestación de las ciencias naturales y sociales.

Pero paralelamente se desarrolla la reflexión filosófica que pondrá los fundamentos de las democracias modernas. ¿Quién va a ser ciudadano? ¿Cómo va a estar distribuido el poder? ¿Cómo se legitimará? Este debate no puede separarse de la polémica sobre lo propio de la feminidad y de la masculinidad. El Rousseau de El Contrato Social (1762), filósofo político, no puede ser desvinculado del Rousseau pedagogo que escribe el Emilio (1762), delineando los roles de hombres y mujeres en la sociedad que está por llegar, la sociedad democrática que hemos heredado. Amparándose en una supuesta ley natural de todos los tiempos pero siendo consciente de la necesidad de un adiestramiento específico, dice: "Toda la educación de las mujeres debe referirse a los hombres. Agradarles, serles útiles, hacerse amar y honrar por ellos, educarlos de jóvenes, cuidarlos de adultos, aconsejarlos, consolarlos, hacerles la vida agradable y dulce: he ahí los deberes de las mujeres en todo tiempo, y lo que debe enseñárseles desde su infancia" (Rousseau, 1998, 545). La división moderna de lo doméstico y de lo público era también una distribución de esferas de actuación de ambos sexos. Esta división guiará a los diputados jacobinos cuando, en plena Revolución Francesa, decreten el cierre de los clubes políticos de mujeres en nombre de las leyes de la Naturaleza.

Dentro de la llustración, podemos distinguir dos corrientes opuestas de pensamiento sobre la diferencia sexual. Una de ellas tiene que ver con el interés por el conocimiento biológico del ser humano y verá en todas las costumbres y papeles de cada sexo una expresión de la naturaleza. Los llamados médicos-filósofos, desde Pierre Roussel al ideólogo Cabanis, explicarán todas las actitudes y funciones de hombres y mujeres desde una perspectiva biologizante que legitimará la exclusión de las mujeres de los estudios superiores, de la política y, en general, de la esfera pública (Fraisse, 1991). Sostendrán que el cerebro y los músculos de la hembra humana son más blandos que los del varón y, por lo tanto, inaptos para un esfuerzo excesivo o prolongado. La función natural de las mujeres, en sus teorías, será exclusivamente la procreación. Siguiendo los consejos de la Higiene, ciencia emergente, el colectivo femenino, afirman los médicos decimonónicos, debe cumplir su misión particular consistente en la mejora de la especie, y dejar a los varones la que les es propia: el perfeccionamiento de la civilización.
La otra corriente se apoya en la convicción ilustrada del poder de la educación para mejorar la sociedad. Encontraremos, por lo tanto, pensadores y pensadoras que insistirán en el carácter social y construido de la desigualdad ${ }^{3}$. Se llega incluso a pensar que las diferencias físicas están determinadas por la civilización. Así, Madame d’Epinay considera que no solo puede decirse que las costumbres varían y son construidas social e históricamente, sino que modelan los cuerpos. La fortaleza de las indígenas americanas le lleva a pensar que la fragilidad y debilidad corporal de las europeas de su tiempo no es más que el efecto de su encierro y de las perniciosas limitaciones a sus movimientos. Olympe de Gouges, dramaturga y pensadora profundamente igualitarista, gran amante de los animales, sostenía en su Declaración de los Derechos de la Mujer y de la Ciudadana (1790) que ninguna hembra de otras especies está tan limitada en su libertad por el macho como lo está la hembra humana. En la comparación entre Naturaleza y Cultura, la humanidad parecía salir mal parada. Más tarde, esta observación daría lugar a especulaciones antropológicas sobre el origen del patriarcado. Del otro lado de la Mancha, con Vindication of the Rights of Woman (Londres, 1794), Mary Wollstonecraft dirige duras críticas a su admirado filósofo Rousseau en lo que concierne a su conceptualización de la mujer. Ve en la deficiente y deformante educación recibida por las niñas el origen de las características femeninas reprobables: "Los hombres se quejan, y con razón, de la insensatez y los caprichos de nuestro sexo, cuando no satirizan con agudeza nuestras impetuosas pasiones y nuestros vicios serviles. Debería responder: ihe ahí el efecto natural de la ignorancia! La mente que solo se apoya en prejuicios siempre será inestable y la corriente avanzará con furia destructiva cuando no haya barreras que rompan su fuerza." (Wollstonecraft, 1994, 127-128). En su Defensa de las mujeres (Madrid, 1726) incluida en el Teatro Crítico Universal, el fraile benedictino Benito Jerónimo Feijoo sostiene que la aparente falta de inteligencia de las mujeres se debe a la carencia de instrucción y a que, encerradas en el hogar, no están acostumbradas a participar en conversaciones doctas (Feijoo, 1726). En el último tercio del XVIII, la ilustrada zaragozana Josefa Amar y Borbón insiste en la capacidad de la educación para erradicar los defectos que se observan en las mujeres: "No hay cosa que no se pueda enseñar en este estado, ni virtud que no se hiciese común, si los que tienen el cargo de la educación supiesen aprovecharse" (Amar y Borbón, 1994, 58). No excluirlas de la instrucción redundará, asegura, en la felicidad de todos y el buen 
orden de la sociedad. Esta tendencia feminista ilustrada, de la que solo he citado algunos representantes, cuestiona, con diferentes matices de intensidad, el carácter innato de las diferencias entre los sexos para defender la universalización de derechos. Interpreta la igualdad de todos los hombres como la igualdad de todos los seres humanos.

Por el contrario, la corriente mayoritaria de la llustración entenderá hombres solo como varones, por lo que la igualdad de todos los hombres será, para Rousseau (Cobo, 1995), Kant (Roldán, 1995) y muchos otros, la igualdad de todos los varones. A principios del siglo XX, esta línea desemboca en la teoría psicoanalítica freudiana sobre la incapacidad de juicio moral en las mujeres. Dado que, según esta teoría, el súper yo se forja en el niño por temor a la castración, la falta de pene impediría a la niña la completa internalización de los valores parentales. La mujer no puede sentir el miedo a perder algo de lo que se sabe desposeída, por lo tanto, tampoco alcanzaría la firmeza de las ideas morales propia del hombre. Para el fundador del psicoanálisis, las reivindicaciones de igualdad feministas provienen, o bien del error y la ingenuidad de pensadores como John Stuart Mill, o bien de un desarrollo inadecuado de la subjetividad en mujeres incapaces de renunciar a la fantasía de ser hombres (Freud, 1967, 490-491). La justificación de la discriminación sexual del siglo XIX toma, con el psicoanálisis, un rumbo más complejo pero no menos eficaz. Introduce la mediación de la mente y de la historia individual entre lo biológico y lo social, intentando explicar, de esta forma, el creciente descontento con respecto a la estricta división de roles de género. El sufragismo había encontrado sus modernos detractores.

\section{LA OPOSICIÓN GÉNERO/SEXO EN EL SIGLO XX}

Si trazamos una genealogía que llegue hasta el siglo XX, la línea igualitaria nos conduce a Simone de Beauvoir, que publica en 1949 El Segundo Sexo. En este clásico del feminismo, la autora sostiene que las mujeres sufren una injusta subordinación. Como pensadora existencialista, entiende la vida humana como proyecto, como elección y libertad. Su afirmación de que "no se nace mujer, sino que se llega a serlo" es una denuncia del Eterno Femenino como mistificación opresiva. Al observar la riqueza de opciones vitales permitidas a los varones y compararla con la maternidad concebida como único destino de las mujeres occidentales de su época, llega a la conclusión de que la sociedad construye la feminidad impidiendo a la mitad de los seres humanos el pleno desarrollo de sus potencialidades.
Hoy en día, desde la enorme cantidad de estudios feministas y de género realizados en más de medio siglo, añadiríamos que tampoco se nace hombre. Tanto hombres como mujeres somos construidos por una serie de mandatos y modelos, por un mundo de lo simbólico en el que estamos todos inmersos. La subjetivación se realiza a partir de elementos que nos son dados. En ocasiones elegimos, otras veces (las más numerosas) repetimos modelos inconscientemente. El concepto de género nos ayuda a descubrir que hay una parte social fundamental en la elaboración de nuestra identidad. Y si miramos este resultado del condicionamiento social desde una perspectiva crítica, puede suceder que algunos de sus aspectos nos disgusten, nos parezcan injustos y queramos cambiarlos.

La antropología ha descrito el sistema de supremacía masculina o patriarcado como aquella sociedad en que los puestos clave de poder (políticos, económicos, militares y religiosos) están ocupados mayoritaria o exclusivamente por varones (Divale \& Harris, 1978). Pero se supone que, en tanto ciencia, debe limitarse a describir, absteniéndose de calificar moralmente. En cambio, desde una perspectiva ética, el pensamiento feminista ha juzgado este sistema y ha considerado que la estratificación por sexos era inadecuada. Esta ha sido la larga lucha de la teoría y la praxis feminista (Amorós y De Miguel, 2005).

Veamos ahora cómo se produjo el encuentro de esta teoría y praxis con el concepto de género creado en el ámbito clínico. El término gender fue utilizado por primera vez a mediados de los años cincuenta por el médico estadounidense John Money, investigador de casos de hermafroditismo, en el marco de la asignación social de sexo a niños con órganos sexuales inciertos. Sostuvo que, a pesar del sexo genético, gonadal y hormonal, un individuo se comportará según el sexo que le asigne el medio familiar en el que se desarrolla. La teoría de Money ha sido muy criticada porque, aunque no niega lo biológico, le da un peso decisivo a los elementos culturales de la subjetivación. Su concepto de rol de género hacía referencia a las actitudes, gestos, conductas, formas de hablar, o moverse y temas preferidos de conversación y juego característicos de las identidades masculina y femenina. Money sostuvo que la fijación de la identidad de género se produce en torno a los dieciocho meses de edad y es el resultado de un proceso en el que intervienen factores biológicos y sociales.

En la década siguiente, el término gender será progresivamente incorporado por las ciencias biomédicas y las ciencias sociales, abriéndose nuevos 
horizontes de investigación. Robert Stoller, profesor de Psiquiatría de la Universidad de California, fue el primer psicoanalista en adoptar la distinción sexo/ género, desarrollando las nociones de identidad de género y núcleo de la identidad de género para estudiar los aspectos psicológicos y ambientales de la masculinidad y la feminidad en los casos de transexualidad (Stoller, 1968).

A finales de los sesenta, las teóricas del feminismo de la llamada "segunda ola" hacen suyo este concepto de gender como una clave que devela relaciones de poder en la organización social a nivel macro y micro. En Política sexual (1969), Kate Millett cita los trabajos de Money y Stoller, como "pruebas positivas del carácter cultural del género, definido como la estructura de la personalidad conforme a la categoría sexual" (Millett, 1995, 77). Al combinar la categoría clínica de género con la noción de política en el sentido frankfurtiano de relaciones de poder, estas pensadoras lo convertirán en arma contra la desigualdad y la opresión. Con él realizarán una dura crítica a la exclusión y marginalización del colectivo femenino.

Tanto K. Millett como S. Firestone contrastarán la condición de género con las de clase y raza (Puleo, 2005a). La participación de esta generación de jóvenes en el movimiento por los derechos civiles de los afroamericanos y en la New Left facilitará la puesta en correlación de la raza y el género al entender que ambas categorías de estatus, a diferencia de la clase, se apoyan fraudulentamente en una marca corporal que no se puede borrar.

Cuando el concepto de género se desarrolla en la Sociología y en el pensamiento político feminista, la identidad sexuada será solo uno de los componentes de un complejo mecanismo de retroalimentación. Como organización social, el sistema de género remite a distintos elementos. Uno de ellos es la división sexual del trabajo. Como se puede constatar transculturalmente, toda sociedad tiende a distribuir tareas según el sexo. Esta segregación suele coincidir con la división de espacios entre una esfera de lo público y otra de lo doméstico, declaradas complementarias pero dotadas de poder y reconocimiento asimétricos. Las sociedades del capitalismo tardío son más fluidas en ese sentido pero ambas esferas continúan altamente generizadas. Tradicionalmente, el ámbito doméstico es el femenino. En él se realizan las labores de mantenimiento de la vida y de reproducción de la fuerza de trabajo y de la especie. Aún hoy, gran parte de la gente vive en hogares tradicionales donde son mujeres las que realizan todas esas tareas de infra- estructura que permiten a los individuos estar listos para actuar en el mundo del trabajo asalariado y de la cultura: preparación de la comida, mantenimiento de la ropa, crianza de los niños, apoyo afectivo, etc. (Murillo, 1996). Las tareas del ámbito doméstico incluyen el cuidado de niños, enfermos y ancianos. Por ello, la Ley de promoción de la autonomía personal y atención a personas en situación de dependencia (BOE no 299 de 15 de diciembre de 2006) no solo está dirigida a asegurar la dignidad y bienestar de las personas dependientes. Su objetivo son también las mujeres cuidadoras. Como han mostrado los estudios de género, a pesar de los cambios recientes en los roles, todavía el cuidado altruista de enfermos y ancianos en el hogar queda mayoritariamente a cargo de las mujeres ${ }^{4}$.

La identidad sexuada es el aspecto psicológico del género fomentado por la división de roles al tiempo que funcional para esta. ¿Qué sentimientos, actitudes y formas de pensar y de actuar caracterizan a los sexos en términos estadísticos ${ }^{5}$ ? Durante mucho tiempo la Psicología ha intentado sistematizar y establecer listados de características opuestas de uno y otro sexo, considerándolas reflejo de la naturaleza interna de cada uno de ellos. Competitividad, valentía, agresividad, entre otros rasgos, definían a los varones frente a las mujeres, consideradas innatamente más emocionales, tiernas, inseguras y temerosas. En cambio, los estudios de género, impulsados por el feminismo, han enfatizado las causas sociales de las diferencias. En algunos países, incluso hoy en día, transgredir las reglas de género puede acarrear la muerte o por lo menos, un duro castigo. En los grupos de pares de cualquier cultura, es común que estas transgresiones sean sancionadas con la burla o el aislamiento. En cuanto al código de la moral sexual, puede afirmarse que todavía hoy es diferente según el género incluso en las sociedades más desarrolladas. En todo caso, puede afirmarse sin lugar a dudas que la bipolarización de la identidad sexuada resultaría en su mayor parte de un fuerte condicionamiento ejercido desde la infancia a través de mecanismos de internalización, imitación, coacción y recompensa. El cultivo de los sentimientos se ha reservado históricamente a las mujeres y se ha reprimido en los varones, lo cual explicaría la tendencia "relacional" femenina. La construcción de la masculinidad gira en torno al poder y la competencia. Con su estudio sobre "la producción de los grandes hombres", premiado por la Académie française, el antropólogo Maurice Godelier ha mostrado cómo se forjan los guerreros en sociedades etnológicas por medio de procedimientos que podríamos llamar "tecnología del género" (Godelier, 1982). Actualmente, los imperios 
siguen construyendo guerreros. Se trata de una interesante cuestión que, a mi juicio, merece ser examinada en profundidad ${ }^{6}$.

Otro componente del sistema de género es el estatus o rango de género que establece la superioridad de los varones y de lo considerado masculino. Aunque ya no se proclame abiertamente como hace un siglo, sigue presente en nuestras actitudes cotidianas de manera inconsciente y atraviesa el conjunto de la cultura. Finalmente, como elemento de la organización social de género, cabe mencionar los discursos de legitimación. Pueden ser mitológicos, religiosos, filosóficos, científicos o artísticos y sirven para justificar las desigualdades entre hombres y mujeres. EI Derecho, la Filosofía, la Religión, la Literatura, las Artes... han apuntalado el sistema de género a través de normas, sanciones, estereotipos y discursos que organizan y jerarquizan el mundo. La hermenéutica de la sospecha de género practica dos formas de revisión de este mundo de lo simbólico. En un primer momento, examina los aspectos discriminatorios que pueda contener. La negación a las mujeres de los derechos reconocidos a los hombres ${ }^{7}$ y la escasez o nula presencia de mujeres en el corpus de la filosofía, la literatura o las artes ${ }^{8}$ son ejemplos del sexismo que los estudios de género han ayudado a poner en evidencia. En un segundo momento, la crítica al mundo de lo simbólico ha advertido un aspecto más oculto e insidioso de la discriminación: el androcentrismo. El prejuicio sexista opera en los mismos criterios de selección de lo excelente, de forma que el problema no reside solo en la exclusión de las mujeres de las actividades prestigiosas de los hombres sino en la clasificación jerarquizada y generizada del mundo. El que ha nombrado y ha definido a los seres, sus cualidades y sus espacios correspondientes ha impuesto también sus propios patrones de evaluación. El androcentrismo impregna la cultura, constituyendo un serio obstáculo para la plena integración de las mujeres. El estatus de género que hace que tendamos inconscientemente a dar más importancia a los hombres, también afecta nuestra evaluación de los objetos y las actividades. Los temas, estilos, costumbres y gustos femeninos son considerados inferiores a los masculinos. Este sesgo de género se encuentra presente en todos los niveles de la cultura y llega a afectar a la misma investigación científica, estableciendo prioridades y distribuyendo de manera desigual el reconocimiento del mérito.

A partir de los años noventa, por efecto del constructivismo radical reinante en el pensamiento postmoderno, el concepto de género tiende a diluir $y$ reemplazar el de sexo. Por su artículo La pensée straight, publicado por primera vez en 1980 en la revista Questions Féministes, Monique Wittig es hoy considerada pionera de esta corriente. Wittig afirmaba que la lesbiana no es una mujer, puesto que mujer es una categoría relacional resultante de la heterosexualidad obligatoria. La lesbiana, afirmaba, es una cimarrona, aludiendo a los esclavos que huían de las plantaciones del Caribe. Se iniciaba, así, una teorización radicalmente constructivista centrada en la sexualidad que conectará con el saber-poder disciplinario foucaultiano.

Heredera del perspectivismo nietzscheano, esta línea de investigación sostiene que no hay realidad que no sea ya interpretada, razón por la que no cabría hablar de sexo como realidad biológica independiente del género. Así, por ejemplo, Thomas Laqueur emprende una detallada historia de las transformaciones de la percepción del cuerpo sexuado en Occidente, buscando mostrar su carácter construido (Laqueur, 1994). En Gender Trouble (1990), Judith Butler aplica al género la noción de performatividad de la teoría de actos de habla de Austin. El género aparece como el resultado de la repetición que actualiza la norma que la precede, ocultando su carácter de norma e inscribiéndose en los cuerpos como "natural". Desde este enfoque asumido por la llamada teoría queer, el concepto de género no se referiría únicamente a hombres y mujeres. No remitiría a una dualidad, sino a una multiplicidad, por lo que se propone la proliferación paródica de los géneros disruptivos (Butler, 1990). Los individuos en los que el sexo, el género y la opción sexual no coinciden serían los nuevos sujetos revolucionarios que permitirían avanzar hacia una sociedad post-género. Aunque está teóricamente vinculado a los planteamientos feministas de la construcción social del género, el objetivo del movimiento queer es otro. La adaptación de un insulto homofóbico (queer) como denominación ha sido entendida como voluntad de mantenerse fuera de la redefinición de la normalidad. Butler ha llamado "performatividad queer" a la capacidad de inversión de las posiciones de enunciación hegemónica que posee la cita descontextualizada en la autodenominación de los "cuerpos abyectos" que se expresan reclamando su propia identidad. La teoría y el movimiento queer no buscan la emancipación de las mujeres, ni la integración normalizada de los gays, sino la abolición del concepto de normalidad a través de la afirmación de las disidencias sexuales más estigmatizadas, como el incesto, y de todos los marginales de las sociedades opulentas (Despentes, 2006). En palabras de Beatriz Preciado, se autocalifica de "post feminista", separándose nítidamente del feminismo 
"blanco y de clase media" que buscaría la igualdad para las mujeres. La teoría contra-sexual de Preciado "define la sexualidad como tecnología y considera que los diferentes elementos del sistema sexo/género denominados "hombre", "mujer", "homosexual", "heterosexual", "transexual", así como sus prácticas e identidades sexuales no son sino máquinas, productos, instrumentos, aparatos, trucos, prótesis, redes, aplicaciones, programas, conexiones, flujos de energía y de información, interrupciones e interruptores, llaves, leyes de circulación, fronteras, constreñimientos, diseños, lógicas, equipos, formatos, accidentes, detritos, mecanismos, usos, desvíos..." (Preciado, 2002, 19). De Foucault y Wittig a Butler y Preciado, pasando por Donna Haraway, se completa la desnaturalización del género iniciada con la llustración. En este principio del nuevo milenio, conviven y polemizan dos formas diferentes de entender y aplicar la hermenéutica de la sospecha de género a la sexualidad: la crítica feminista a la unión de Eros y Thanatos ${ }^{9}$ y la reivindicación queer de las prácticas transgresivas.

Un interrogante sobre las consecuencias políticas de la disolución total del sexo en el género: el movimiento queer pide la desaparición de la mención del sexo en los documentos de identidad. Esta demanda, en principio, me parece coherente con la afirmación del individuo frente a la obligatoriedad de identificarse con un sexo. Pero ¿cómo se podría articular con las políticas de acción positiva? ¿La disolución del par hombre/mujer, tal como es propuesta por la teoría queer, es favorable a las mujeres que, al fin y al cabo, siguen existiendo?

\section{APUNTE FINAL SOBRE NATURALEZA Y CULTURA}

Me he referido al androcentrismo como el sesgo patriarcal de la cultura vinculado al rango de género. Todo lo que se considera masculino es más valorado, y lo femenino, asimilado a la Naturaleza, es menos apreciado. La crítica al androcentrismo es una crítica a nuestra cultura en tanto producto de una historia de dominación masculina. Insisto en que no se trataría de una esencia masculina, sino de una historia en la que los varones han ocupado permanentemente una posición hegemónica por causas sobre las que los especialistas aún discuten.

Se ha observado que la noción de hombre forjada en la Grecia clásica estaría vinculada a la existencia de la esclavitud, ya que esta institución se alimentaba de los prisioneros conseguidos en las acciones bélicas. La exaltación del espíritu por encima de la materia, de lo masculino sobre lo femenino, que encontramos en
Platón sería, según Nancy Hartsock, una legitimación involuntaria de la guerra. Animaba a arriesgar la vida a los varones griegos y consolaba de su posible pérdida (Hartsock, 1985). Una ideología que sostiene la inferioridad de la Vida, de la Naturaleza y del Cuerpo es altamente funcional en una sociedad patriarcal guerrera. Nuestra especie comenzó a conceptualizarse a sí misma sin dar cabida a las mujeres y a sus experiencias en el proceso. El concepto de ser humano (hombre) que hemos heredado está históricamente relacionado con sistemas de dominación de seres humanos (esclavos), mujeres y Naturaleza (Puleo, 2005b). Aristóteles afirma en su Política que el hombre libre tiene su propio fin en sí mismo. En cambio, sostiene, los esclavos, las mujeres y los animales no poseen un fin en sí mismos. Dárselo corresponde al hombre libre. En su clasificación ontológica piramidal, la naturaleza aparece vinculada a las mujeres, los esclavos, las emociones, el cuerpo, los animales. El Hombre es un fin en sí porque es intelecto, dominio racional legítimo de los seres inferiores.

Nuestros conceptos de Naturaleza y Cultura han sido históricamente construidos y provienen de una historia "impura" de dominación y explotación que ya es hora de revisar. Una de las aportaciones más interesantes de la teoría ecofeminista reside en la puesta en relación del análisis del androcentrismo con el antropocentrismo. La arrogancia con respecto a los demás seres vivos y la ilusión de que nuestra especie puede sobrevivir aunque destruya la Naturaleza es un ejemplo de lo que se ha llamado "la lógica del dominio" o "la lógica del Amo" (Plumwood, 1993). Hoy, la teoría y la praxis ecofeministas apuntan a horizontes regulativos emancipatorios para otro mundo posible de libertad, igualdad y sostenibilidad (Puleo, 2011).

Querría cerrar estas líneas, pues, insistiendo en que las aportaciones de la teoría crítica de género no se reducen a mostrar la desigualdad y a exigir que las mujeres accedan a puestos de decisión en las mismas condiciones que los hombres, o a que las identidades sexuales disidentes sean reconocidas. La hermenéutica de la sospecha de género nos lleva mucho más allá. Las personas de buena voluntad podrían aprovechar la ocasión para transformar la sociedad. Muchas voces llaman a esta tarea, pero habremos de desconfiar de todas las que resten importancia a la demanda de igualdad o reintroduzcan un discurso mistificador (Amorós, 2005). Idealizar en este tema no es ni conveniente ni correcto. Podríamos, incluso, volver a la vieja discusión medieval y renacentista que enfrentaba a misóginos y defensores de las damas en torno a cuál era el sexo excelente (Puleo, 2000). Las mujeres 
no somos maravillosas pero quizás podamos aportar algo desde nuestra experiencia de los márgenes, por ejemplo, la ética del cuidado (López de la Vieja, 2004). Es posible incorporar elementos descuidados o devaluados sin necesidad de hipostasiar o exagerar las virtudes del colectivo femenino; y, al mismo tiempo, pedir la igualdad (López de la Vieja, 2000). Tenemos que reclamar que continúen y se intensifiquen las políticas de acción positiva dirigidas a superar la situación de desventaja del "segundo sexo", un proceso que, según cálculos de expertos, al ritmo actual tardará unos cuatrocientos años en consumarse.
La implementación de la categoría de género, en tanto tematización feminista de las relaciones entre los sexos, ha facilitado que, por primera vez en la Historia, el Derecho se haya marcado por objetivo avanzar hacia la igualdad entre mujeres y hombres. También ha permitido una clara mejora de la condición legal y social de las minorías sexuales. Si a estos extraordinarios logros sumamos la posibilidad de una profunda revisión de nuestro mundo de lo simbólico y de nuestra visión de la naturaleza, podemos concluir que se trata de una de las nociones de frontera entre lo biológico y lo cultural más revolucionarias de los últimos tiempos.
1 La violencia doméstica no debe ser confundida con la violencia de género ya que sus víctimas son también niños y ancianos y no se explica por la ideología sexista. Numerosas formas de violencia de género tienen lugar fuera del ámbito doméstico como, por ejemplo, la violación o la prostitución forzada. Hay que señalar, sin embargo, que la Ley española restringe la definición de "violencia de género" a la violencia contra la mujer que se produce en las relaciones familiares y de pareja, difiriendo así del sentido más amplio que le diera la teoría feminista.

2 El "hembrismo" o ideología de la superioridad femenina sería el inexistente opuesto simétrico a machismo, no el feminismo que históricamente se ha desarrollado desde sus inicios como una teoría y un movimiento social que reivindica el respeto y la igualdad de derechos y oportunidades entre los sexos.

3 Para consultar una selección de textos de esta corriente minoritaria que he llamado “Ilustración olvidada”, ver Puleo, 1993.
4 Los resultados de la encuesta sobre cuidados a las personas mayores en los hogares españoles del IMSERSO del año 2004 mostró que el $84 \%$ de las personas que atendían mayores dependientes son mujeres. Debe señalarse, sin embargo, que con respecto a la encuesta de 1994 se observa un incremento de hijos varones implicados, pasándose del $10 \%$ al $19 \%$. Datos del 2010 continuaban recogiendo un $83 \%$ de mujeres entre las personas que asumen el cuidado de los dependientes.

5 El reconocimiento de las diferencias entre individuos que, en ocasiones, contradice las predicciones de la socialización de género no es incompatible con generalizaciones de alta probabilidad estadística. Sostener lo contrario sería negar la validez de las ciencias sociales.

6 Particularmente interesante resulta el planteamiento de Myriam Miedzian (Miedzian, 1995).

7 El derecho al voto por el que debieron luchar las sufragistas es un ejemplo paradigmático. En culturas no occidenta- les, actualmente las mujeres reclaman, entre otros, el derecho a la herencia en igualdad con el hombre o el derecho a la tenencia de la tierra.

8 Basta recorrer el índice de los manuales al uso para advertir la escandalosa ausencia de las creadoras. A pesar de las dificultades materiales, existieron mujeres que escribieron, pintaron, esculpieron y compusieron, pero solo ahora se comienza, parcialmente, a recordarlas. Este reconocimiento suele hacerse en obras especializadas en el quehacer cultural de las mujeres, por lo general, no es todavía una actitud incorporada a la normalidad.

9 La tematización de la sexualidad divide al feminismo en las tres últimas décadas. Las posiciones teóricas se bifurcan y oponen a partir de la forma en que conciben las relaciones entre deseo, violencia, voluntad de dominio y sistema de género. Ambas conectan con el pensamiento filosófico previo sobre la sexualidad a través de los conceptos de revolución y transgresión sobre los que pivotan respectivamente (Puleo, 2007). 
Amar y Borbón, J. (1994). Discurso sobre la educación física y moral de las mujeres (ed. M. a Victoria López-Cordón). Madrid: Cátedra.

Amorós, C. (1997). Tiempo de feminismo. Sobre feminismo, proyecto ilustrado $y$ postmodernidad. Madrid: Cátedra.

Amorós, C. (2005). La gran diferencia y sus pequeñas consecuencias... para las luchas de las mujeres. Madrid: Cátedra.

Amorós, C.; Miguel, A. de (eds.). (2005). Historia de la teoría feminista. De la Ilustración a la globalización. Madrid: Minerva.

Beauvoir, S. (1998). El Segundo Sexo. Madrid: Cátedra.

Butler, J. (1990). Gender Trouble. Feminism and the Subversion of Identity. New York: Routledge.

Cobo, R. (1995). Fundamentos del patriarcado moderno. Jean-Jacques Rousseau. Madrid: Cátedra.

De Miguel, A.; Cobo, R. (1997). “Implicaciones políticas del feminismo". En Quesada, F., Filosofía política I. Ideas políticas y movimientos sociales, Enciclopedia Iberoamericana de Filosofía. Madrid: Trotta.

Despentes, V. (2006). King Kong Théorie. Paris: Grasset.

Divale, W.; Harris, M. (1978). "The male supremacist complex: Discovery of a cultural invention". American Anthropologist, 80, pp. 668-671.

Feijoo, J. (1726). "Defensa de las mujeres". En Teatro crítico universal. Discursos varios en todo género de materias, para desengaño de errores comunes. Tomo I. Discurso 16, IX, 57. Biblioteca Feijoniana. Proyecto Filosofía en español (http://www.filosofia.org/bjf/ bjft116.htm, consultado el 1 de abril de 2008).

Fraisse, G. (1991). Musa de la razón. La democracia excluyente y la diferencia de los sexos. Madrid: Cátedra.
Fraser, N. (1997). Iustitia interrupta. Reflexiones críticas desde la posición postsocialista, trad. Magdalena Holguín e Isabel Jaramillo. Bogotá: Siglo del Hombre Editores, Universidad de los Andes.

Freud, S. (1967). "Algunas consecuencias psíquicas de la diferencia sexual anatómica". Obras completas, vol. III. Madrid: Biblioteca Nueva.

Godelier, M. (1982). La production des Grands Hommes. Pouvoir et domination masculine chez les Baruya de Nouvelle Guinée. París: Ed. Fayard.

Hartsock, N. (1985). Money, Sex and Power. Boston: Norteastern University Press.

Laqueur, T. (1994). La construcción del sexo. Cuerpo y género desde los griegos hasta Freud. Madrid: Cátedra.

López de la Vieja, T. (2000). “Ética de la diferencia, política de la igualdad". En López de la Vieja, T. (ed.), Feminismo: del pasado al presente. Salamanca: Universidad de Salamanca, pp. 51-76.

López de la Vieja, T. (2004). La mitad del mundo. Ética y crítica feminista. Salamanca: Universidad de Salamanca.

Miedzian, M. (1995). Chicos son, hombres serán. Cómo romper los lazos entre masculinidad y violencia. Cuadernos inacabados, ed. Horas y Horas.

Millet, K. (1995). Política sexual. Madrid: Cátedra.

Murillo, S. (1996). El mito de la vida privada: de la entrega al tiempo propio. Madrid: Siglo XXI.

Plumwood, V. (1993). Feminism and the Mastery of Nature. New York: Roudledge.

Puleo, A. (ed.) (1993). La llustración olvidada. La polémica de los sexos en el siglo XVIII. Barcelona: Anthropos.

Puleo, A. (ed.) (1996). Figuras del Otro en la Ilustración francesa. Diderot y otros autores. Madrid: Escuela Libre Editorial.

Puleo, A. (ed.) (2008). El reto de la igualdad de género. Nuevas perspectivas en Ética y Filosofía Política. Madrid: Biblioteca Nueva.
Puleo, A. H. (2005a). "Lo personal es político: el surgimiento del feminismo radical". En Amorós, C.; Miguel, A. de (eds.). Historia de la teoría feminista. De la llustración a la globalización. Madrid: ed. Minerva, pp. 35-67.

Puleo, A. H. (2005b). "Del ecofeminismo clásico al deconstructivo: principales corrientes de un pensamiento poco conocido". En Amorós, C.; Miguel, A. de (eds.), Historia de la teoría feminista. De la llustración a la globalización. Madrid: ed. Minerva, pp. 121-152.

Puleo, A. H. (2007). "Philosophy, Politics and Sexuality". En Oliver, A.; Femenías, M. L., Feminist Philosophy in Latin America and Spain. Atlanta: VIPS RODOPI ed., pp. 187-195.

Puleo, A.H. (2011). Ecofeminismo para otro mundo posible. Madrid: Cátedra.

Preciado, B. (2002). Manifiesto contrasexual. Madrid: ed. Ópera Prima.

Roldán, C. (1995). "El reino de los fines y su gineceo: las limitaciones del universalismo kantiano a la luz de sus concepciones antropológicas". En Aramayo, R.; Muguerza, J.; Valdecantos, A. (comps.). El individuo y la historia. Antinomias de la herencia moderna. Barcelona: ed. Paidós.

Rousseau, J.-J. (1998). Emilio o De la Educación. Madrid: Alianza.

Rubio, A. (1997). Feminismo y ciudadanía. Sevilla: Instituto Andaluz de la Mujer.

Salzman, J. (1992). Equidad y género. Una teoría integrada de estabilidad y cambio. Madrid: Cátedra.

Stoller, R. (1968). Sex and Gender. New York: Science House.

Stoller, R.; Herdt, G. (1982). "The development of masculinity: A crosscultural contribution". Journal of the American Psychoanalytic Association, 30, pp. 29-59.

Wollstonecraft, M. (1994). Vindicación de los Derechos de la Mujer. Madrid: Cátedra. 